\title{
IoT Based Shirodhara
}

\author{
Indumathi $\mathrm{J}^{\mathrm{a}, 1}$ and Sendhilkumar $\mathrm{A}^{\mathrm{b}}$ \\ ${ }^{a}$ IEEE Senior member \\ ${ }^{\mathrm{b}}$ Professor, Department of Information Science and Technology, Anna University, \\ Chennai - 600 025.Tamilnadu, India
}

\begin{abstract}
The contemporary pandemic scenario of COVID- 19 has brought to surface the efficacy of old health care wisdom in inhibition and care of diseases where contemporary medicine deceptively wants a real cure. Undeniably, viral diseases for the fascinating vitality of their causal organisms, top this wish list. Ultimately the world seems to be enthusiastic to pay attention about old health care approaches to control viral pandemics if these are found well-intentioned in handling such situations. One such demand is to energetically or intelligently use the therapeutic devices especially the Shirodhara device, at the convenience, anytime, anywhere in a teleconsultation mode. The Shirodhara device design is to be in a manageable form without trailing the legitimacy and principals of Ayurveda. The main elements used in the device comprises of a sensor for perceiving the temperature, a pump for salvaging the medicine, programming device to control the temperature, and regulate the heater and a wavering pipe for free flow of the medicine. The device is premeditated in such a way to evade the faults and snags produced while doing the procedure Shirodhara. Hence, this device is built which is portable, cost effective; it provides a technologically enhanced Shirodhara instrument curtailing the practice of medicine and man power for the procedure.
\end{abstract}

Keywords. Shirodhara, oil, tele-consultation, portable, sensors.

\section{Introduction}

The term Shirodhara is taken from the duple Sanskrit words "shiro" (head) and "dhara" (flow). The traditional ayurvedic sacred scripture of Charak Samhita and Susruta Samhita says that Shirodhara is also called by innumerable other dialect names as: Shiro Sheka, Sirothara, Parisheka, Shiro Parisheka, Dhara, and Shirashe. From time immemorial, the ayurvedic treatment by name Shirodhara is used to lessen mental stress. The Shirodhara treatment is used to offer a calming feeling to the mind and physique. All the particulars related to the deployment of Shirodhara are elucidated in traditional texts such as 'Dharakalpah'; wherein, some physical parameters like the altitude of drop, nature of fluid, the substantial of dhara pot etc. are endorsed [1].

\footnotetext{
${ }^{1}$ Indumathi J, IEEE Senior member.

E-mail: indumathi@annauniv.edu,dr.j.indumathi@gmail.com.
} 


\section{Types Of Shirodhara Massage}

A judiciously selected liquid (based on the symptoms) at a fixed temperature is made to fall freely on the forehead unceasingly for a fixed amount of time and at a selected velocity to generate an impetus force. The liquid is made to drop down from a dhara pot held at a standard elevation of 4 angulas for dhara over head; for other build part, it is ended from a elevation of 12 angulas. If there is a progressive disease then, the normal procedure is done departed from above cited rules. Usually, 2-3 litres of the carefully chosen liquids are used for the 1-hour long session [2].

Types of Shirodhara Massage- The Shirodhara Massages are based on the various types of herbal oils or infusions, and it is classified into the following types:

- Dugadha Dhara (Ksheerdhara): In this type the key ingredient is milk.

- Jala Dhara (Aqueous formulation): To smoothen the Pitta imbalance in the body, coconut water is chiefly used.

- Ksheer Dhara: To smoothen the Vata and Pitta predominant headaches, stress, insomnia, and anxiety, milk infused with herbs are chiefly used.

- Kwatha Dhara (Decoction): built on the recognized condition or dosha imbalance, the main element in kwatha dhara encompasses the decoctions got from the numerous herbs.

- Sneha Dhara or oil Shirodhara: In this type herbal oils used are called tela or ghee.Herbal oils are mixed from various essential oils.Lakshadi oil or Chandan Bala Lakshadi oil is used to treat Pitta and Dhanwantaram is used to treat Vata disorders. To smoothen the Vata and Kapha imbalances, warm oil is chiefly used. To smoothen the Pitta imbalances, cool oils (room temperature) are chiefly used. Tepid herbal ghee or Saraswat ghee is used for the treatment of the Pitta that is accompanied by Vata vitiation.

- Taila Dhara (Thaila Dhara): In this type either only one oil or a combination of many ayurvedic oils are used.

- Takra Dhara (Thakradhara): To smoothen the aggravated Vata in the body, buttermilk infused with special herbs are chiefly used.

\section{Types Of Oils Used In Shirodhara Massage}

Liquids used in Shirodhara that are opted by consultants include are, Animal milk, buttermilk, Buttermilk processed with Indian Gooseberry, Chandanadi thailam, Clarified butter (ghee), Coconut oil, Coconut water, Decoctions of herbs, especially licorice, decoctions particularly those encompassing licorice and Dhanwantharam thailam, herbal ingredients, Karpasasthyadi thailam, kasaya (medicated water), Ksheer bala tailam (a mixture of Bala herb paste, sesame oil, and cow's milk), ksheerabala oil, mahanarayana oil, Milk only, milk processed with herbs and Narayana thailam, sesame oil, warm milk, water

\subsection{Which Oil Is Best For Shirodhara?}

Based on the physiological condition and Vatic imbalance of an individual. The kind of the liquid selected is subject to the patients' health condition. Even the basic sesame oil, or oils that are antioxidant rich and oils with energetic elements like sesamin, sesaminol 
and sesamol, induce not only the serotonin movement in the brain but also pacifies and quietness the head, discharges stressful settings and encourages slumber. The oils assorted with nervine herbs are also helpful for curing people with post-traumatic trauma syndrome.

\section{Related Work}

Divya et al. formulated a hypothesis concerning the system of Shirodhara. The hypothesis, talks about the conversion of latent potential energy (PE) in the liquid into kinetic energy (KE) during free drop. The authors also elucidate that the tumbling liquid over the patient's forehead, creates an impetus which causes an alteration in voltage which kindles the nerve compulsions or heightens the nerve compulsion conduction [3].

Uebaba et al. [4] characterized Shirodhara in an arbitrary and regulation cluster of subjects realized in the control prostrate position by the robotic system [5,6]. The efficacy of Shirodhara is enumerated using physiological parameters such as heart rate, $\mathrm{CO}_{2}$ output, blood pressure, electrocardiogram (ECG) and electroencephalogram (EEG) to quantity the electrical bustle of heart and brain $[4,5,7]$.

Obviously, the machinery of Shirodhara is byzantine involving

- Creation of a force due to influence

- transformation of impression force into mechanical pressure waves

- conversion of mechanical pressures into neurological signals and

- change of neurological signals into enduring physiological effects like tranquillity of the patients.

Even though a mechanism of treatment is hypothesized by [3] and the efficiency of Shirodhara are documented by [5]; no significant literature exists in understanding the mechanics of process involved in Shirodhara.

\section{Working Mechnaism}

\subsection{Reason For The Pouring Of Shirodhara Oil Onto The Forehead}

The herbs or herbal ingredients, infused liquids are squirted on the forehead and scalp so that the muscles of the cranium, which have several peripheral nerves or numerous subtle nerve endings or energetic points that are right away linked to the hypothalamus of the brain get soothened. It further arouses the numerous energetic points all about the head and enhances the blood flow.

\subsection{Treatment Procedure Of Shirodhara Massage}

Step 1. The entire procedure is routed to steer the mind and body to indulge in a state of profound rest. Before 5 to 10 minutes properly knead the head and scalp using a right amount of oil/liquid.

Step 2. The patient lies in a prostrate position on droni/ Shirodhara table. If essential, place a small pad or cloth under the neck for correct support. 


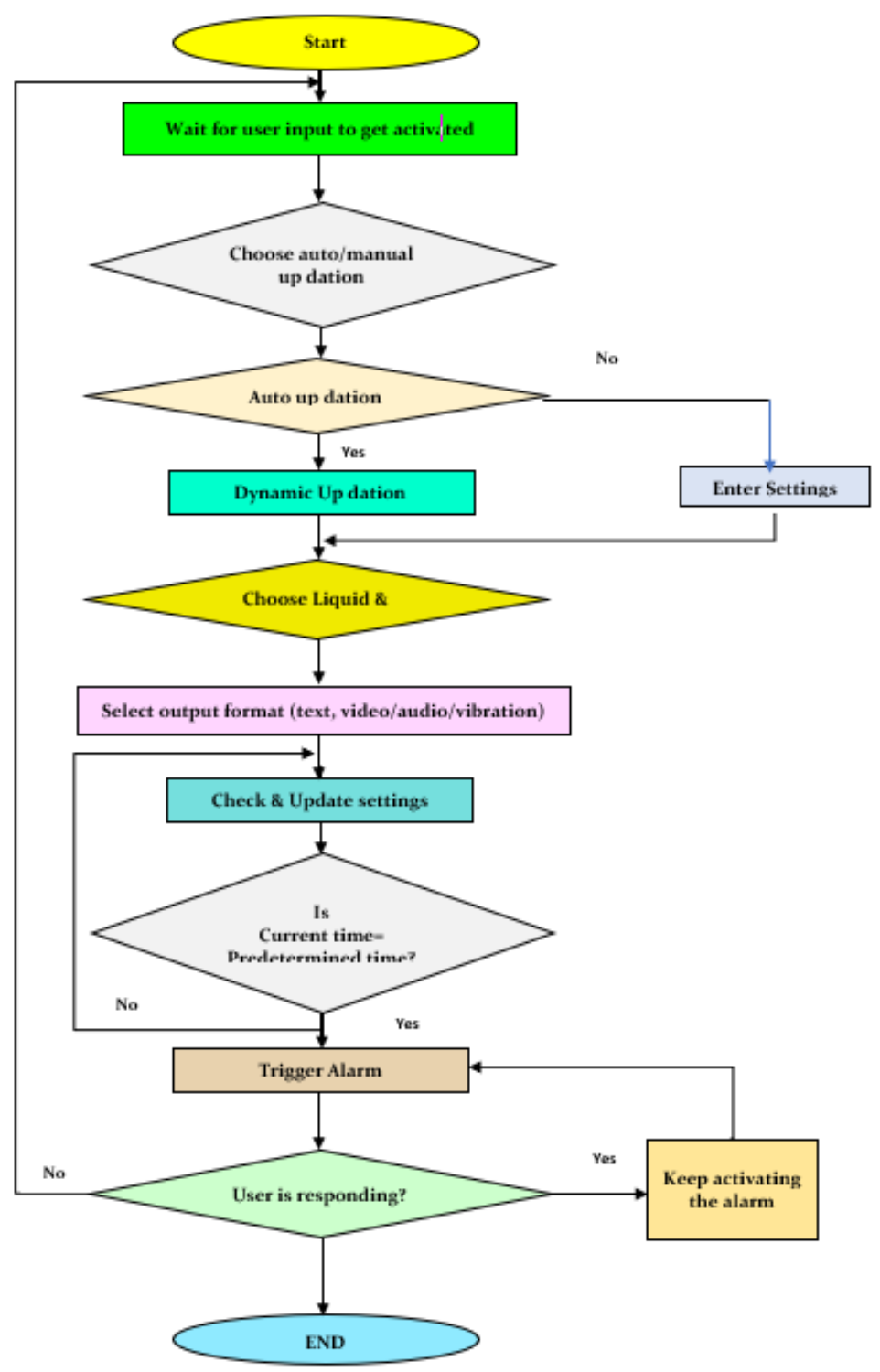

Figure 1. Flow chart -Steps performed Shirodhara process/procedure.

Step 2a. The dhara pot (which can be made of earthen/copper/brass material) has a pothole at the nethermost of about to the size of a little finger (standard size) hung above the subject $[1,8]$. The wick assembly in the Shirodhara pot is akin around four angulas (approximately $7.5 \mathrm{~cm}$ ) above, from the subject's forehead [1]. Shirodhara pot and the forehead distance ought to be about 10 $\mathrm{cm}$. Perfect the Shirodhara pot or equipment so as to ensure that the liquid from the pot tumbles down straight onto the forehead. 
Step 3. Fill the Shirodhara pot, with the carefully selected oil, and necessary herbs; slowly open the nozzle and regulate the flow of the herbal oil or the herbal liquids over the head and forehead of the patient.

Step 4. As the oil drips/flows continuously over the forehead ask the patient to lessen and enjoy the feeling looming from the oil as it is dispersed over the head.

Step 5. Under the supervision of a curative assistant, the Shirodhara pot is equivocate or waver along the length of the forehead ensuring incessant flow; and the fluid should go from left to right, crosswise part of the forehead and vice versa.

Step 6. Accumulate the brimming superfluous oil from the forehead, on the table, rewarm it to endure the precise temperature of the Shirodhara oil. The liquid is heated/rewarmed to the patient's body temperature or to a temperature that is comfortable to the patient and spurted via Shirodhara pot along the length of the forehead $[1,8]$.The warmed oil is poured back into the pot and this same way, it gets recycled till the end of the procedure.

Step 7. Upon completion of treatment, the patient is recommended to take rest.

Step 8. The procedure persists for about 20 to 30 minutes.

Step 9. A light head massage is also effected on the patient during the process.

Step 10. Upon accomplishment of the Shirodhara massage, wipe off the oil or fluids from the temple area of the patient.

Step 11. Recommend the patient to rest for 30 to 60 minutes, so that the oil slowly oozes deep inside the head.

\section{What Is Shirodhara Good For?}

The myriad healing paybacks of these herbal liquids used for the massage aids in the treatment of a host of vigor conditions (tranquil, restful, and comforting) and it is good for, Aids in Mental Focus and Concentration, Allergic rhinitis, Lowers High Blood Pressure, Cognitive Abilities. Depression -anti-stress, anti-depressive and anti-anxiety, Eye diseases and Vision Problems, Hair- Reduces the Hair Loss and Fatigue and greying of hair, Headaches - Relieves Chronic Headaches and Migraines, Hearing damageminimises, Hypertension, Insomnia, Intuition, Rouses Intuition, Memory loss, Meniere's disease, Neurological disorders, psoriasis-like certain types of skin diseases, Reduces / Diminishes Anxiety, Relieves /Reduces Stress/ Post-Traumatic Stress Disorders, Sinusitis, Sleep Quality - Enhancing Sleep Quality -Soothes Vata Doshas -Stabilizes Nervous System, Tinnitus and Hearing loss, Tinnitus, Vertigo.

The treatment thus caters to the soothing, easing, restful effects on the mind, nurtures and calms the doshas but also expansively used for giving a numberless of vigor incongruities together with stress, despair, wakefulness, high blood pressure, hemicrania, etc. It also enhances the mystical alertness and aids to establish a recent linking to the inner soul. 


\section{Proposed Smart Shirodhara}

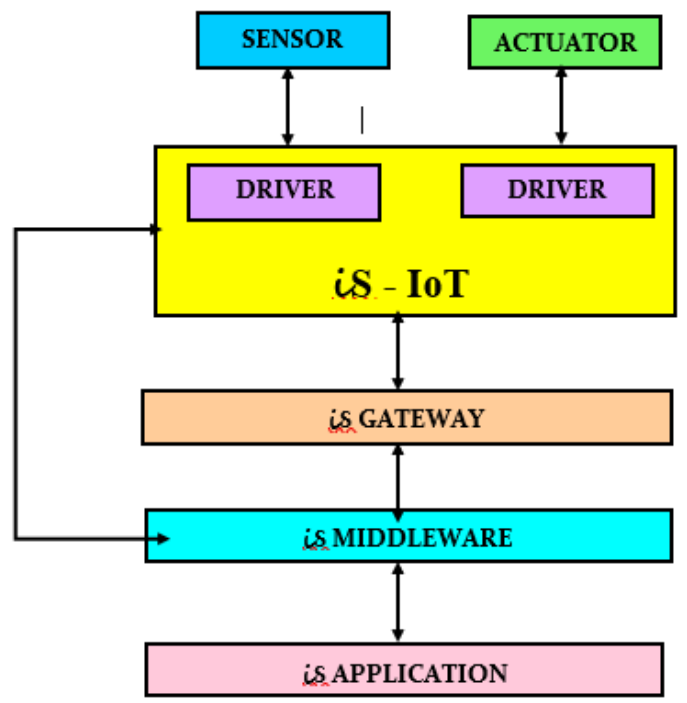

Figure 2. Layered block diagram of Integrated IoT based iS system

Figure 2 is a typical layered block diagram representation of the Integrated IoT based iS system, in accordance with the exemplary embodiment in the invention. The schematic of the Integrated IoT based iS system is shown in figure 3 and is also described in the ensuing sections.

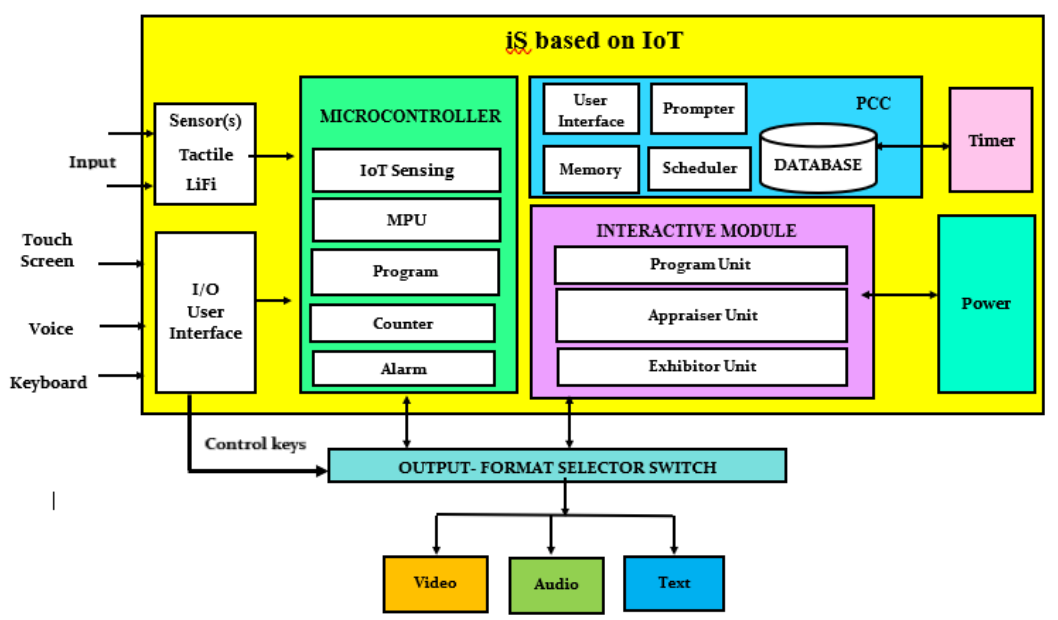

Figure 3. schematic representation of the integrated iS

Figure 3 shows a schematic representation of the integrated iS blocks with customization facility. There are four modules, namely, the water dispensing module, an 
Interactive (process/procedure) caller module, the display module and a sensing module, all of which are connected to a microcontroller (for process and control). It includes at the heart components like microcontroller, the MPU, RAM, ROM, sensor(s), an alarm, dispensation circuitry, and concerned modules.

(i) iS central device - iS device is a hardware component. The iS is linked to the Sensors and/or Actuators either by wire or wirelessly and it integrates all the components. iS is a processor with sufficient storage capacity to run the programmed software and to establish a link to the IoT Integration Middleware.

(ii) Microcontroller -This gives the iS system its behaviour and it has a small MPU that runs the software. The microcontroller may be an Arduino board, a raspberry pi, a beagle bone or the like.

(iii) Micro Processing Unit (MPU) - Micro processing unit (MPU) components are the ALU(arithmetic logic unit which is used to execute arithmetic and logical operations), and the $\mathrm{CU}$ (control unit which is used to extract instructions from memory, decode it and executes them, also calls the ALU as per necessity).

(iv) Memory - In the Micro-controller, more exactly, the MPU needs the programs to do a specific task which is a set of commands. The Microcontrollers memory is of 2 types, namely, Read-only memory (ROM) and random-access memory (RAM).

(v) Bus - Bus is used for the transfer of data and consist of 8, 16 or even more wires. The Address bus is 16-bit and is used to assign address and identify memory positions. The Data bus is 8 bits and is used to indicate an ASCII character and is used to carry on data.

(vi) Oscillator - The on-chip crystal oscillator (for stable oscillation) is the time source for CPU.

(vii) Interrupts- An interrupt is the signal to the processor directed by external hardware or software to show that an event needs immediate service in the process/procedure cycle.

(viii) Gateway - Gateway helps to link the Process/procedure Device to additional systems and it offers indispensable technologies and mechanisms to construe amongst the various protocols, communication technologies, and payload formats.

(ix) IoT Integration Middleware- The IoT Integration Middleware (IoTIM) provides a mixing layer for diverse varieties of Sensors, Actuators, Devices, and Applications. It is liable for (i) getting data from the connected Devices, (ii) processing the received data, (iii) providing the received data to linked Applications, and (iv) regulating Devices.

(x) Application- It is the software that runs the IoT Integration Middleware (i) to increase understanding into the physical environment via sensors and/or (ii) to deploy the physical world by controlling physical actions using Actuators. The invention discloses an iS, small, portable, smart, economical, employs only a limited number of sensors, diminishing the cost of posture recognition accuracy.

(xi) Power- The iS may also include a power source such as a battery which powers the microcontroller, the sensor(s), the alarm, timer. 
(xii) Counter- The counter for instance, is updated in response to a valid output signal, to create a visible signal (both audio, video).

(xiii) Communication unit bestows the iS with communication capabilities. It can be anything ranging from internal communications to options like Bluetooth and ZigBee's typically either a Bluetooth or ZigBee.

The iS may also include a power source such as a battery which powers the microcontroller, the sensor(s), the alarm and timer. The output signal from the sensor(s) may be analog or digital depending upon the microcontroller specifications.

\section{Conclusion}

The contemporary pandemic scenario has enforced people to stay indoors, has curtailed the frequent visits to the hospital and has encouraged to go for teleconsultations. But to tackle the steady rising number of COVID- 19 it is noticed that certain therapies cannot come to a standstill or be stopped for want of proximity of skilled professionals. Further to utilise the efficacy of old health care wisdom without any inhibition at will, anywhere, anyplace the device is proposed for real cure. One such demand is to energetically or intelligently use the therapeutic devices especially the Shirodhara device, at the convenience, anytime, anywhere in a teleconsultation mode. The Shirodhara device design is to be in a manageable form without trailing the legitimacy and principals of Ayurveda.

\section{References}

[1] Pavana J, Manoj S. Keraliya Chikitsa paddhati: Padmasri. DR. K. Rajagopalan ayurveda series-3. 2010.

[2] Soumita B. Shirodhara Massage: Benefits, Uses, Procedure, Oils, Treatment And Side Effects [Internet]. 2020 [cited 2020 Sep 20]. Available from: https://www.netmeds.com/health-library/post/shirodharamassage-benefits-uses-procedure-oils-treatment-and-side-effects

[3] Divya K, Tripathi JS, Tiwari SK. An appraisal of the mechanism of action of shirodhara. Annals of Ayurvedic Medicine. 2013;2:114-7.

[4] Uebaba K, Xu FH, Tagawa M, Asakura R, Itou T, Tatsue T, Taguchi Y, Ogawa H, Shimabayashi M, Hisajima T. Using a healing robot for the scientific study of Shirodhara. IEEE engineering in medicine and biology magazine. 2005 Apr 4;24(2):69-78.

[5] Uebaba K, Xu FH, Ogawa H, Tatsuse T, Wang BH, Hisajima T, Venkatraman S. Psychoneuroimmunologic effects of Ayurvedic oil-dripping treatment. The journal of alternative and complementary medicine. 2008 Dec 1;14(10):1189-98.

[6] Xu F, Uebaba K, Ogawa H, Tatsuse T, Wang BH, Hisajima T, Venkatraman S. Pharmaco-physiopsychologic effect of Ayurvedic oil-dripping treatment using an essential oil from Lavendula angustifolia. The Journal of Alternative and Complementary Medicine. 2008 Oct 1;14(8):947-56.

[7] Dhuri KD, Bodhe PV, Vaidya AB. Shirodhara: A psycho-physiological profile in healthy volunteers. Journal of Ayurveda and integrative medicine. 2013 Jan;4(1):40-4.

[8] Lavekar GS, Menon TV. Practical handbook of Panchakarma procedures. 2009. 